\title{
DIGITALCOMMONS
}

—@WAYNESTATE —

Wayne State University

9-10-2013

\section{Exploring the Relative Importance of Spatial and Environmental Variation on the Craniometrics of the Modern Portuguese}

Katherine E. Weisensee

Clemson University, kweisen@clemson.edu

\section{Recommended Citation}

Weisensee, Katherine E., "Exploring the Relative Importance of Spatial and Environmental Variation on the Craniometrics of the Modern Portuguese" (2013). Human Biology Open Access Pre-Prints. Paper 31.

http://digitalcommons.wayne.edu/humbiol_preprints/31 
Title: Exploring the Relative Importance of Spatial and Environmental Variation on the Craniometrics of the Modern Portuguese

Running header: Spatial Variation in the Craniometrics of Portuguese

Author: Katherine E. Weisensee

Affiliation: Department of Sociology and Anthropology, Clemson University, 132 Brackett Hall, Clemson, SC 29634-1356. kweisen@clemson.edu

Key words: spatial autocorrelation, craniometrics, geography, isolation-by-distance, neutral model, secular changes 


\begin{abstract}
Previous research on the causes of craniometric variation within and among human populations has invoked both genetic and environmental explanations. Recent studies of modern populations in the United States and Portugal, among other populations, suggest that changes in environmental conditions have resulted in significant changes in cranial morphology. While similar changes in cranial morphology have been observed in genetically diverse populations, these populations do not appear to be converging on a common form. This study seeks to understand the role that population history and environmental variation play in explaining craniometric variation in the modern Portuguese. Using three-dimensional craniometric data collected from an identified skeletal collection from Lisbon, Portugal, this research examines the relationship between cranial morphology and place of birth. Two hypotheses are tested with regard to craniometric variation. The first asks whether phenotypic variation is related to geographic distance in the sample and therefore accurately represents genetic relationships. The second explores whether the significant secular changes observed in the sample obscure the population history reconstructed using craniometric data. The results demonstrate a significant relationship between geography and cranial morphology in the modern Portuguese sample. The clinal distribution to the craniometric variation is similar to what has been reported in some studies of molecular DNA from the Portuguese. The results show that cranial morphology reflects both the geography and genetic history of the sample and, furthermore, that secular changes in the population neither obscure nor erase this pattern. This study illustrates that even when secular changes have a significant impact on
\end{abstract}


cranial morphology, they do not impede researchers' ability to reconstruct genetic relationships using craniometric data. 
An understanding of the spatial variation among human populations is a fundamental question in biological anthropology. When investigating population history it is important to examine the effects of spatial variation and the role of adaptation and natural selection in shaping human genetic diversity. Spatial variation impacts population history in that populations that are geographically close to one another may be biologically similar because migration is more likely to occur between local populations, which thus increases the likelihood of gene flow. Common ancestry may also influence spatial variation as founding populations tend to result in a clinal patterning to genetic similarity. Finally, populations that are geographically close often share similar environments and therefore natural selection may act on the populations in similar ways (Relethford 2010). Previous research suggests environmental effects including climate, diet, and postindustrial environmental conditions affect cranial morphology within and among human populations (Carlson and Van Gerven 1977; Fabra and Demarchi 2011; Jantz and Meadows Jantz 2000). Other research suggests that human craniometrics follow a neutral model of evolution and reflect population history with the same results as other genetic markers (Betti et al. 2009; Relethford 2002; Roseman 2004; von Cramon-Taubadel 2009). Much of the recent research examining the neutral model of craniometrics uses global samples to determine whether spatial variation follows predicted patterns from human populations that migrated out of Africa. Documented skeletal collections from recent populations can also be useful in examining the relationship between environmental effects and population history effects on craniometrics. These collections are useful for exploring such questions because they provide extensive historical documentation 
for each individual-information that is not generally available in most other skeletal collections.

The environmental conditions that have impacted human populations over the past 200 years have proven to have a significant impact on cranial morphology (Jantz and Meadows Jantz 2000). Because of the short period of time in which changes in cranial morphology are observed, such changes cannot be said to have resulted from adaptations due to natural selection. Instead, these morphological changes are likely the result of changes in cranial growth patterns as populations have experienced changes in mortality patterns, nutritional availability, and activity patterns (Weisensee and Jantz 2011). These environmental variables have had a significant impact on human populations and appear to have produced similar changes in cranial morphology across genetically diverse populations, specifically resulting in changes in the cranial base region. Although modern environmental conditions appear to result in changes in cranial morphology in many populations, population history may also be examined using cranial morphology.

The relative importance of plasticity in modifying craniofacial morphology and perhaps obscuring the genetic relationships between populations has been a fundamental question since Boas (1912) published the findings of his immigrant study. As a result of Boas's work, some researchers have questioned the use of craniometrics in reconstructing population relationships. Relethford (2004) discusses the relative contributions of plasticity and genetics for understanding craniofacial morphology. He points out that Boas's data suggest that a small component of the observed variation in the sample is explained by developmental plasticity, that these differences do not obscure differences among the ethnic groups, and that genetic 
differences explain a large component of the variation. Researchers' specific questions must, therefore, dictate the level of exploration, whether it be through the lens of developmental plasticity or genetic differentiation. Genetic variation may be controlled for to look at developmental plasticity, or developmental plasticity may be controlled for to examine genetic questions.

Several researchers have examined global patterns of craniometric variation and shown that, in general, as geographic distance increases so does phenotypic distance. This confirms that patterns of population relationships reconstructed from craniometric data are similar to patterns observed using other types of genetic markers, including classical genetic markers and DNA markers (Eller 1999; Relethford 2004). Roseman and Weaver (2007) have argued that researchers can formulate simple and testable predictions by testing hypotheses from craniometric data based on a neutral theory of evolution whereby variation within and among populations is explained as a result of mutation, genetic drift, and gene flow. Only after rejecting the neutral hypothesis should researchers invoke adaptive hypotheses to explain the variation observed within and among populations. Furthermore, the authors suggest that natural selection does not play a significant role in the craniometric variation observed in recent human populations.

The correspondence between phenotypic variation and geography provides one way to measure the usefulness of craniometrics for examining the relative importance of genetic history and local environmental adaptation in human populations. An isolation-by-distance model proposes a simple spatial pattern whereby genetic distances are related to geographic distances between populations. One method used to examine the variation among populations 
within a geographic area is spatial autocorrelation. This method allows for an assessment of biological variation to determine whether variation follows an isolation-by-distance model, results from founding populations and exhibits a clinal distribution, or is randomly distributed across space (Barbujani 1987).

Place of birth is one way of examining spatial variation in human populations, although this information is not commonly known in undocumented skeletal collections. The individuals sampled in the current study were all buried in Lisbon, but many were born outside the city between the early 1800s and the mid-1900s. The time period sampled in this study is unique in that it marks a period of intense rural-to-urban migration in Portugal (Birmingham 1993; Rodrigues Veiga, Moreira, and Fernandes 2004). The many individuals in the sample who were born elsewhere in Portugal but buried in Lisbon are likely representative of this large-scale migration. Place of birth can, therefore, be used to assess the spatial variation present across Portugal during the time period sampled. Thus, the current study examines two questions: First, does the craniofacial variation in the modern Portuguese follow an isolation-by-distance model? Second, given the previous research that has demonstrated significant secular changes in this sample (Weisensee and Jantz 2011), do secular changes erase or obscure our ability to accurately reflect population history in this sample?

\section{Materials and Methods}

This study uses a sample from the Lisbon skeletal collection. This collection consists of identified individuals disinterred from three large cemeteries in Lisbon, Portugal (Cardoso 2006). The birth dates in the sample range from the early 1800 s to the mid-1900s. All of the individuals in the sample were buried in Lisbon, yet many were born outside of the city. Data 
were collected from 290 individuals with known places of birth. Sixteen of the 18 administrative districts of Portugal are represented in the sample. The two districts not represented in the sample are Braga and Viana do Castelo.

All of the data used in this study were collected by the author. First, three-dimensional landmark coordinates were collected using a Microscribe 3DX digitizer. A total of 67 bilateral and midsagittal points were collected from each individual (Table 1). Next, the threedimensional coordinates were aligned to a common coordinate system using a Procrustes superimposition. Procrustes superimposition fixes variation between specimens related to size, rotation, and location and allows for comparisons of shape differences among individuals. The Procrustes aligned coordinates were then subjected to a Principal Components Analysis, and the first 30 principal components were used in the subsequent analyses. The first 30 principal components represent $79.4 \%$ of the variation in the sample. Individuals were grouped according to their administrative district of birth. The data were also divided into North, Central, and South areas, with the North and Central areas divided by the Douro River and the Central and South areas divided by the Tagus River in order to more easily visualize spatial patterns in the data. This type of regional division has been used in several other genetic studies (Beleza et al. 2006). A canonical discriminant analysis was subsequently performed using the PROC CANDISC procedure in SAS 9.1 (2002-2004). This analysis allowed for the visualization of geographic differences between administrative districts.

A Procrustes distance matrix based on the Procrustes coordinates was calculated between administrative districts. Because the Lisbon sample is much larger in comparison to the other districts, 100 random samples of 10 individuals were taken from the larger Lisbon 
sample and used to generate 100 Procrustes distance matrices. A second distance matrix was created in which the non-interstate road distance between each administrative capital was calculated using Google Maps. A Mantel test then compared the Procrustes and geographic distance matrices in order to evaluate the correlation between biological and geographic distances. Separate Mantel tests evaluated each of the 100 smaller Lisbon samples to ensure that the large sample did not bias the results. Spatial autocorrelation was analyzed using a global method (Smouse and Peakall 1999) in which the geographic distances were divided into five distance classes equal to $100 \mathrm{~km}$ distances. A correlogram representing the correlation between the Procrustes distance and the five distance classes was constructed using GenAIEx 6.5 (Peakall and Smouse 2006). The autocorrelation coefficient ( $r$ ) was calculated; this value is closely related to Moran's I. The autocorrelation coefficient provides a measure of the genetic similarity among the districts within a specified distance class and provides a method of evaluating the isolation-by-distance model.

The latitude and longitude of each administrative district capital was also recorded. A multivariate multiple regression analysis of the first 30 principal components with latitude, longitude, and year of birth was performed using PROC REG in SAS 9.3 (2002-2010). Partial correlation tests used the resulting continuous variables to determine whether secular changes in the sample obscured variation related to geography. Finally, shape variation among the regions was explored via a comparison of the mean shape of the Northern districts with the mean shape of the Southern districts.

\section{Results}

A plot of the first two canonical variates derived from the Portuguese districts is seen in 
Figure 1 ; the two axes account for $37 \%$ of the variation in the sample. The $x$-axis demonstrates a general North-South gradient to the variation, with most Southern districts clustering together on the left side of the plot and the Northern districts clustering on the right side. The plot shows that Lisbon is more similar to the Southern districts in comparison to other Central districts. The second axis also separates North and South, although there is little differentiation between Central and Northern regions as defined by the Douro River. There does not appear to be any differentiation between coastal and interior provinces based on the first two canonical variates.

The Mantel test comparing the Procrustes distance matrix and the geographic distance matrix found a significant correlation for the overall sample $(r=0.3439, p=0.0210$ from 999 randomizations). The Mantel tests of the 100 randomly generated samples consisting of 10 individuals each from the Lisbon sample had $p$-values $<0.05$ in 98 out of 100 tests. The results from the Mantel tests demonstrate that, as geographic distance increases, the Procrustes distances also increase. These findings suggest that the sample used in the current study fits an isolation-by-distance model. The results of the autocorrelation analysis also show a significant spatial pattern to the data (Figure 2). The spatial correlogram illustrates a clinal distribution in which positive, significant autocorrelations are found at small distances and negative, significant autocorrelations characterize large distances.

The effect of the latitude and longitude of the individuals' district of birth was also examined. The results of the regression analysis demonstrate that latitude and longitude both have a significant effect on cranial shape. Partial tests of year of birth, latitude, and longitude show that, when controlling for any of the two factors, the third factor remains significant (see 
Table 3). This finding indicates that both temporal variables and spatial variables significantly affect cranial morphology independently.

The morphological changes associated with spatial differentiation are illustrated in Figure 3. The cranial landmark that exhibits the most dramatic change is the maximum frontal breadth, which is located more superiorly in the South than in the Northern and Central districts. The frontal breadth is also narrower in the Southern districts. Overall, the typical Southern cranium tends to have a slightly more inferiorly projecting cranial base, a more anteriorly positioned prosthion, and a more superiorly located lambda. Interestingly, Boldsen (2000) identifies frontal breadth as a measure of genetic differentiation in his medieval Danish samples, and in the current study the region of the crania that shows the most spatial differentiation is the frontal breadth.

\section{Discussion}

This study investigated two hypotheses. The first hypothesis examined whether the craniofacial variation in this sample fits an isolation-by-distance model. The significant correlation between the Procrustes distance matrix and the geographic distance matrix shows that as geographic distance increases so does the Procrustes distance and, therefore, demonstrates that craniofacial variation is related to spatial variation. Populations that are geographically close may share a genetic similarity because gene flow is mediated by spatial distance, because founding populations may have been similar in geographically localized populations, or because populations that are in close proximity to each other may share similar adaptations to local environmental conditions. Portugal is a small country with no extreme environments represented; its regions lack, for example, extremely high altitudes and extreme 
cold. It therefore seems unlikely that the observed spatial variation is caused by environmental adaptation to local conditions; instead the spatial variation likely reflects the genetic history of the country, specifically gene flow and founding populations. Moreover, the correlogram (Figure 2) indicates that the spatial variation follows a clinal distribution, thus suggesting founding populations played a significant role in shaping the variation observed in the sample. The North-South gradient of variation observed in this study has been documented in previous genetic studies of the Portuguese using mitochondrial DNA (Gonzalez et al. 2003; L. Pereira, Prata, and Amorim 2000; V. Pereira et al. 2010). Conversely, studies that examined some Y-SNP and Y-STR markers in Portuguese males and other studies of mitochondrial DNA did not find a significant relationship between genetic diversity and geography (Beleza et al. 2006; L. Pereira et al. 2000); these studies found that genetic diversity is randomly distributed across the country and that the Portuguese population is genetically homogeneous. Barbujani (2000) states that geographic randomness would generally be surprising in population genetic studies, and as a rule geographically close populations exchange more migrants than distant populations. However, the difference between the findings of some of the genetic studies and those of the current study may be due to temporal differences in the samples. It may also result from differences in sampling strategies. In the current study, for example, place of birth was identified for individuals who emigrated to Lisbon during their lifetimes. In the genetic studies, samples were collected from people living in the various administrative districts today. It may be that the Lisbon migrants were somehow different from the individuals who remained. Finally, the genetic variation as reflected in the morphology of the crania may provide a different genetic signal in comparison to the $\mathrm{Y}$ chromosome and mtDNA genetic markers that 
were previously examined by other researchers.

The second hypothesis examines the question of whether, given the Lisbon sample's previously reported secular changes, that sample's population history remains observable. In other words, do the short-term environmental effects related to secular changes over 150 years impede researchers' ability to reconstruct population history using craniometric data? The results of this study suggest that, within the Lisbon sample, the underlying genetic structure as reflected in the spatial structure is not obscured by secular changes. Rather, both the spatial and temporal aspects of population differentiation can be observed in the sample.

Consequently, researchers do not lose the ability to identify the underlying genetic structure with the occurrence of secular changes. This finding is similar to the results reported by Relethford (2004) in his discussion of the re-analysis of the Boas data, in that the secular changes observed in Boas's sample explain a small part of the variation and the genetic differences among the populations are maintained. Analysis of the secular trends in the United States also confirm these findings. Jantz and Meadows Jantz (2000) have shown that in the United States, Black and White males and females have experienced significant secular changes in their cranial morphology over the past 200 years. All of these populations are apparently responding to the same changes in environmental conditions, although they are not converging on a common form (Jantz and Meadows Jantz 2000). This research has demonstrated that the underlying genetic structure remains observable in spite of the secular changes acting on populations in the United States. Different levels of variation may be examined; the variation produced by secular changes may be controlled for to look at genetic differences; and the genetic differences may be controlled for to look at environmental responses. "One person's 
noise may be another person's signal," (Relethford 2004:381). This also holds true for the Lisbon sample, whereby changes in environmental conditions are clearly shaping cranial morphology, yet the underlying spatial and genetic structure of the population can still be seen.

Previous research on the secular changes in the cranial morphology of the Lisbon skeletal collection suggests that accelerated growth patterns may explain the observed changes (Weisensee and Jantz 2011). Throughout the twentieth century, the Portuguese experienced trends toward an earlier menarche (Padez 2003a), earlier maturation in the dentition (Cardoso 2008), and taller stature (Padez 2003b); these processes are also likely associated with some of the changes observed in the crania. Analysis of an ontogenetic series from the same collection found that as individuals age, the cranial base moves superiorly. When growth is completed earlier, the cranial base may be located more inferiorly and result in an overall taller cranial base height. The trend toward earlier maturation has been observed in many populations that have undergone significant changes in environmental conditions over the past 200 years, including in the United States, and studies on secular changes in the crania of U.S. populations have similarly found significant increases in the cranial base height (Jantz and Meadows Jantz 2000).

In addition to research suggesting that changes in the pattern and timing of growth and development processes impact cranial morphology, other research has suggested that changes in masticatory behavior and diet have had a significant impact on cranial morphology within populations. For instance, Carlson and Van Gerven (1977) explained variation in a Nubian sample spanning more than 13,000 years as resulting from changes in diet during the shift from foraging to food production. Other studies have also found that changes in diet related to 
masticatory function may result in changes in cranial morphology during the transition to food production (Larsen 1995). Little et al. (2006) suggested that changes in the cranial morphology of a modern Mexican sample were related primarily to a change in maize processing which resulted in an overall softer diet.

Other researchers have demonstrated that craniometric variation within populations may be due to adaptations to specific climatic conditions. Specifically, in his analysis of global populations, Relethford (2010) identified three groups that did not fit a neutral model of phenotypic variation which would predict a correlation between geographic and phenotypic variation. Two of the populations that Relethford identified, the Buriat and Greenland samples, were outliers particularly due to the large size of the crania. These populations appear to exhibit modification in the crania due to adaptation to environmental conditions, specifically extreme cold; thus, their increased cranial size conforms to the expectation predicted from Bergmann-Allen rules of climatic adaptation. The third outlier group was the Peru sample, and the cranial morphology in this sample may be related to early settlement patterns in South America. Several other craniometric studies examining South American populations have also suggested that climate influences cranial morphology. Nasal shape, in particular, has been suggested to be strongly influenced by temperature and altitude and to respond to selective pressures related to thermoregulation (Bernal et al. 2010; Fabra and Demarchi 2011; GonzalezJose et al. 2005; Hernandez et al. 1997).

The foregoing studies suggest a range of explanations for craniometric variation within populations that incorporates both developmental and adaptational explanations. Roseman and Weaver (2007) recommended human craniometric studies initially test the neutral forces 
of evolution; when researchers find departures from the neutral model, other adaptational explanations may then be appropriate to explain the observed variation. In the current study, the phenotypic variation appears to fit a neutral model whereby geographic distance and phenotypic distance follow a clinal distribution that is similar to that seen in some genetic studies from Portugal. On the other hand, the secular changes that have been observed in the Lisbon sample suggest environmental changes, too, have had a significant impact on the sample's phenotypic variation. However, these secular changes have neither obscured nor erased the genetic variation as reflected in the cranial morphology of the sample.

Research from the modern period and from documented collections like the Lisbon skeletal collection contributes to our understanding of the processes that shape craniometric variation in a number of ways. First, documented collections allow researchers to associate individuals with specific changes in environmental conditions, and the existence of historical records of changes in the genetic structure of the population allows for a more thorough understanding of the processes that are shaping population changes. Additionally, the data obtained from documented collections enhance researchers' ability to create models of population change which can then be used to interpret observations in earlier populations for which extensive documentation does not exist. The availability of many different data sources enables researchers to develop a more in-depth level of understanding of identifiable characteristics of populations in transition. Moreover, the known data available from modern collections offer bioarchaeological researchers new opportunities to test many of their assumptions.

In summary, this research has demonstrated that craniometric data can be useful for 
documenting the spatial relationships in human populations and for analyzing the underlying evolutionary processes that created the observed patterns of variation. Moreover, this research shows that, even when secular changes modify the cranial morphology, these modifications do not diminish researchers' ability to reconstruct population relationships based on craniometric data.

\section{Literature Cited}

Barbujani, G. 1987. Autocorrelation of gene frequencies under isolation by distance. Genetics 117:777-782.

Barbujani, G. 2000. Geographic patterns: How to identify them and why. Hum. Biol. 72:133153.

Beleza, S., L. Gusmão, A. Lopes et al. 2006. Micro-phylogeographic and demographic history of Portuguese male lineages. Ann. Hum. Genet. 70:181-194.

Bernal, V., S. I. Perez, P. N. Gonzalez et al. 2010. Spatial patterns and evolutionary processes in southern South America: A study of dental morphometric variation. Am. J. Phys. Anthropol. 142:95-104.

Betti, L., F. Balloux, W. Amos et al. 2009. Distance from Africa, not climate, explains withinpopulation phenotypic diversity in humans. Proc. R. Soc. B Biol. Sci. 276:809-814.

Birmingham, D. 1993. A Concise History of Portugal. Cambridge: Cambridge University Press.

Boas, F. 1912. Changes in the bodily form of descendants of immigrants. Am. Anthropol. 14:530-562

Boldsen, J. L. 2000. Human demographic evolution: Is it possible to forget about Darwin? 
Research report. Odense: Danish Center for Demographic Research.

Cardoso, H. F. V. 2006. Brief communication: The collection of identified human skeletons housed at the Bocage Museum (National Museum of Natural History), Lisbon, Portugal. Am. J. Phys. Anthropol. 129:173-176.

Cardoso, H. F. V. 2008. Secular changes in body height and weight of Portuguese boys over one century. Am. J. Hum. Biol. 20:270-277.

Carlson, D. S., and D. P. Van Gerven. 1977. Masticatory function and post-Pleistocene evolution in Nubia. Am. J. Phys. Anthropol. 46:495-506.

Eller, E. 1999. Population substructure and isolation by distance in three continental regions. . Am. J. Phys. Anthropol. 108:147-159.

Fabra, M., and D. A. Demarchi. 2011. Geographic patterns of craniofacial variation in preHispanic populations from the Southern Cone of South America. Hum. Biol. 83:491-507. González, A. M., A. Brehm, J. A. Pérez et al. 2003. Mitochondrial DNA affinities at the Atlantic fringe of Europe. Am. J. Phys. Anthropol. 120:391-404.

González-José, R., F. Ramírez-Rozzi, M. Sardi et al. 2005. Functional-cranial approach to the influence of economic strategy on skull morphology. Am. J. Phys. Anthropol. 128:757771.

Hernández, M., C. L. Fox, and C. García-Moro. 1997. Fueguian cranial morphology: The adaptation to a cold, harsh environment. Am. J. Phys. Anthropol. 103:103-117. Jantz, R., and L. Meadows Jantz. 2000. Secular change in craniofacial morphology. Am. J. Hum. Biol. 12:327-338.

Larsen, C. S. 1995. Biological changes in human populations with agriculture. Annu. Rev. 
Anthropol. 24:185-213.

Little, B. B., P. H. Buschang, M. E. P. Reyes et al. 2006. Craniofacial dimensions in children in rural Oaxaca, southern Mexico: Secular change, 1968-2000. Am. J. Phys. Anthropol. 131:127-136.

Padez, C. 2003a. Secular trend in stature in the Portuguese population (1904-2000). Ann. Hum. Biol. 30:262-278.

Padez, C. 2003b. Social background and age at menarche in Portuguese university students: A note on the secular changes in Portugal. Am. J. Hum. Biol. 15:415-427.

Padez, C., and M. A. Rocha. 2003. Age at menarche in Coimbra (Portugal) school girls: A note on the secular changes. Ann. Hum. Biol. 30: 622-632.

Peakall, R., P. E. Smouse. 2006. Genalex 6: Genetic analysis in excel. Population genetic software for teaching and research. Mol. Ecol. 6:288-295.

Pereira, L., M. J. Prata, and A. Amorim. 2000. Diversity of mtDNA lineages in Portugal: Not a genetic edge of European variation. Ann. Hum. Genet. 64:491-506.

Pereira, L., M. J. Prata, M. Brión et al. 2000. Clinal variation of YAP+ Y-chromosome frequencies in Western Iberia. Hum. Biol. 72:937-944.

Pereira, V., V. Gomes, A. Amorim et al. 2010. Genetic characterization of uniparental lineages in populations from Southwest Iberia with past malaria endemicity. Am. J. Hum. Biol. 22:588-595.

Relethford, J. H. 2002. Apportionment of global human genetic diversity based on craniometrics and skin color. Am. J. Phys. Anthropol. 118:393-398.

Relethford, J. H. 2004. Boas and beyond: Migration and craniometric variation. Am. J. Hum. Biol. 
$16: 379-386$.

Relethford, J. H. 2010. Population-specific deviations of global human craniometric variation from a neutral model. Am. J. Phys. Anthropol. 142:105-111.

Rodrigues Veiga, T., M. J. G. Moreira, and A. A. Fernandes. 2004. Social changes and better health conditions of the Portuguese population 1974-2000. Hygiea Internationalis 4:255-276.

Roseman, C. C. 2004. Detecting interregionally diversifying natural selection on modern human cranial form by using matched molecular and morphometric data. Proc. Natl. Acad. Sci. 101:12824-12829.

Roseman, C. C., and T. D. Weaver. 2007. Molecules versus morphology? Not for the human cranium. Bioessays 29:1185-1188.

Smouse, P. E., and R. Peakall. 1999. Spatial autocorrelation analysis of individual multiallele and multilocus genetic structure. Heredity 82:561-573.

von Cramon-Taubadel, N. 2009. Revisiting the homoiology hypothesis: The impact of phenotypic plasticity on the reconstruction of human population history from craniometric data. J. Hum. Evol. 57:179-190.

Weisensee, K. E., and R. L. Jantz. 2011. Secular changes in craniofacial morphology of the Portuguese using geometric morphometrics. Am. J. Phys. Anthropol. 145:548-559. 
Table 1. List of landmark abbreviations and definitions of landmarks used in the study.

\begin{tabular}{|c|c|c|}
\hline $\begin{array}{l}\text { Midline or } \\
\text { right/left }\end{array}$ & Landmark & Definition \\
\hline $\mathrm{m}$ & 4 corn & Point of intersection of palatine and maxillary bones \\
\hline$r / l$ & alar & Most lateral point on nasal aperture \\
\hline$r / l$ & ast & Point where lambdoid, parietomastoid, and \\
\hline & & occipitomastoid sutures meet \\
\hline$r / l$ & aub & $\begin{array}{l}\text { Point on lateral aspect of root of zygomatic process at } \\
\text { deepest incurvature }\end{array}$ \\
\hline $\mathrm{m}$ & bas & $\begin{array}{l}\text { Point where anterior margin of foramen magnum } \\
\text { intersects midsagittal plane }\end{array}$ \\
\hline $\mathrm{m}$ & brg & Point where coronal and sagittal sutures intersect \\
\hline$r / l$ & dac & $\begin{array}{l}\text { Point of intersection of frontolacrimal and } \\
\text { lacrimomaxillary sutures }\end{array}$ \\
\hline$r / l$ & ecm & $\begin{array}{l}\text { Most lateral point on outer surface of aveolar margin of } \\
\text { maxilla }\end{array}$ \\
\hline$r / l$ & ect & Most lateral point on orbital margin \\
\hline$r / l$ & eur & Most laterally positioned point on cranial vault \\
\hline$r / l$ & flac & Most medial point on foramen lacerum \\
\hline$r / l$ & fma & $\begin{array}{l}\text { Point where zygomaticofrontal suture crosses orbital } \\
\text { margin }\end{array}$ \\
\hline
\end{tabular}




\begin{tabular}{|c|c|c|}
\hline $\mathrm{r} / \mathrm{l}$ & $\mathrm{fmt}$ & Most lateral point on zygomaticofrontal suture \\
\hline$r / l$ & fob & Most lateral point on margin of foramen magnum \\
\hline $\mathrm{m}$ & glb & Most anterior point on frontal bone \\
\hline $\mathrm{m}$ & hor & Point of attachment of vomer to sphenoid bone \\
\hline $\mathrm{r} / \mathrm{l}$ & jug & $\begin{array}{l}\text { Point in notch between temporal and frontal processes } \\
\text { of zygomatic bone }\end{array}$ \\
\hline $\mathrm{m}$ & lam & Point where sagittal and lambdoid sutures meet \\
\hline $\mathrm{r} / \mathrm{l}$ & mast & Most inferior, lateral point on mastoid process \\
\hline $\mathrm{m}$ & met & $\begin{array}{l}\text { Point where frontal elevation above chord from nasion- } \\
\text { bregma is greatest }\end{array}$ \\
\hline $\mathrm{m}$ & nas & $\begin{array}{l}\text { Point of intersection of nasofrontal suture and } \\
\text { midsagittal plane }\end{array}$ \\
\hline $\mathrm{r} / \mathrm{l}$ & nasi & $\begin{array}{l}\text { Most inferior point of intersection of nasomaxillary } \\
\text { suture }\end{array}$ \\
\hline$r / l$ & nass & $\begin{array}{l}\text { Point of intersection of frontonasal, frontomaxillary, } \\
\text { and nasomaxillary sutures }\end{array}$ \\
\hline $\mathrm{r} / \mathrm{l}$ & nlhi & Most inferior point on nasal aperture \\
\hline $\mathrm{m}$ & opg & Most posteriorly projecting point on cranial vault \\
\hline $\mathrm{m}$ & ops & $\begin{array}{l}\text { Point where posterior margin of foramen magnum is } \\
\text { intersected by midsagittal plane }\end{array}$ \\
\hline $\mathrm{m}$ & paspt & $\begin{array}{l}\text { Point of maximum projection in midline of parietal } \\
\text { bones }\end{array}$ \\
\hline
\end{tabular}




\begin{tabular}{|c|c|c|}
\hline $\mathrm{r} / \mathrm{l}$ & por & Point superior to external auditory meatus \\
\hline $\mathrm{m}$ & pro & $\begin{array}{l}\text { Most anterior point on alveolar border of maxilla } \\
\text { between central incisors in midsagittal plane }\end{array}$ \\
\hline $\mathrm{m}$ & spglb & $\begin{array}{l}\text { Point between glabella and frontal eminence in } \\
\text { midsagittal plane of frontal bone }\end{array}$ \\
\hline$r / l$ & sph & lintersection of sphenofrontal and coronal sutures \\
\hline $\mathrm{m}$ & ssp & $\begin{array}{l}\text { Point of deepest curvature between prosthion and } \\
\text { anterior nasal spine }\end{array}$ \\
\hline $\mathrm{m}$ & sta & Most posterior point on posterior nasal spine \\
\hline $\mathrm{r} / \mathrm{l}$ & ste & $\begin{array}{l}\text { Point on cranial base at intersection of sphenoid anc } \\
\text { temporal bones near spine of sphenoid bone }\end{array}$ \\
\hline $\mathrm{r} / \mathrm{l}$ & $\operatorname{stp}$ & $\begin{array}{l}\text { Point of intersection of inferior temporal line with } \\
\text { coronal suture }\end{array}$ \\
\hline $\mathrm{r} / \mathrm{l}$ & wnb & $\begin{array}{l}\text { Point of minimum distance between left and right } \\
\text { nasomaxillary sutures }\end{array}$ \\
\hline $\mathrm{r} / \mathrm{l}$ & $\mathrm{xfb}$ & Maximum breadth of frontal bone \\
\hline$r / l$ & zygom & Most inferior point on zygomaticomaxillary suture \\
\hline $\mathrm{r} / \mathrm{l}$ & zygoo & $\begin{array}{l}\text { Intersection of zygomaticomaxillary suture at orbital } \\
\text { margin }\end{array}$ \\
\hline $\mathrm{r} / \mathrm{l}$ & zyti & Most inferior point on zygomaticotemporal suture \\
\hline $\mathrm{r} / \mathrm{l}$ & zyts & Most superior point on zygomaticotemporal suture \\
\hline
\end{tabular}


Table 2. Sample size by administrative district.

\begin{tabular}{|c|c|}
\hline Administrative District & $\mathrm{n}$ \\
\hline Aveiro & 9 \\
\hline Beja & 5 \\
\hline Bragança & 5 \\
\hline Castelo Blanco & 14 \\
\hline Coimbra & 11 \\
\hline Évora & 7 \\
\hline Faro & 12 \\
\hline Guarda & 8 \\
\hline Leiria & 11 \\
\hline Lisbon & 160 \\
\hline Portalegre & 5 \\
\hline Porto & 5 \\
\hline Santarém & 16 \\
\hline Setúbal & 8 \\
\hline Vila Real & 6 \\
\hline
\end{tabular}


Table 3. Results of regression analysis.

\begin{tabular}{lcc}
\hline & Wilks's lambda & p-value \\
\hline PC1-PC30 = Year of birth, latitude, longitude & 0.4469 & $<0.0001$ \\
Year of birth, controlling for latitude and longitude & 0.7876 & 0.0003 \\
Latitude and longitude, controlling for year of birth & 0.5746 & $<0.0001$ \\
\hline
\end{tabular}


Figure 1. Canonical variates plot of the administrative districts in Portugal. The districts are divided regionally in order to more clearly visualize general spatial patterns.

Figure 2. Spatial correlogram from autocorrelation analysis with five distance classes equal to $100 \mathrm{~km}$ each. Diamond markers indicate $p<0.05$.

Figure 3. (A) Frontal and (B) lateral views of spline plot with wireframe showing mean shape of Northern districts and lines showing magnitude and direction of change of Southern districts. The vectors are exaggerated by a factor of 2 for greater legibility. 


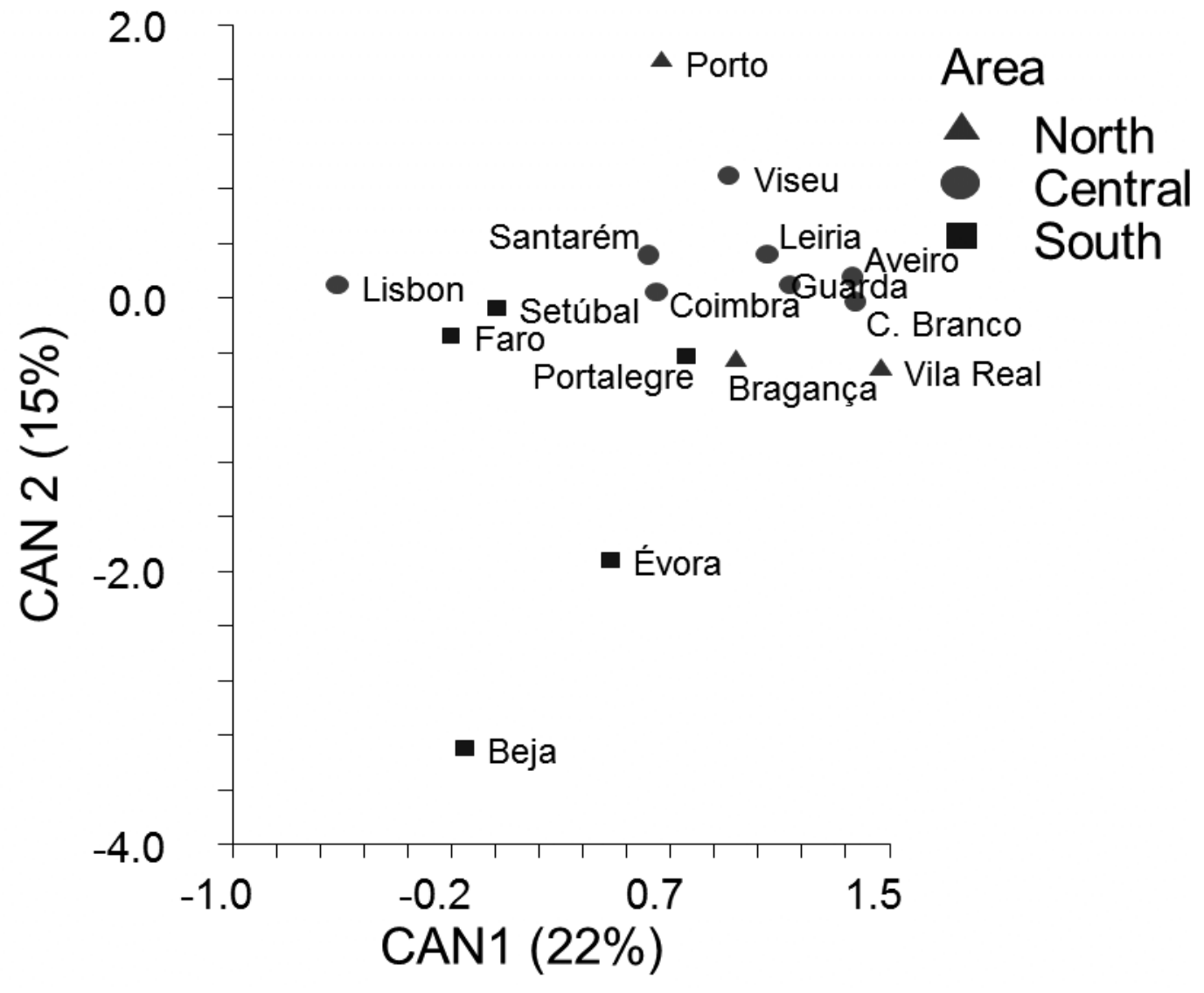




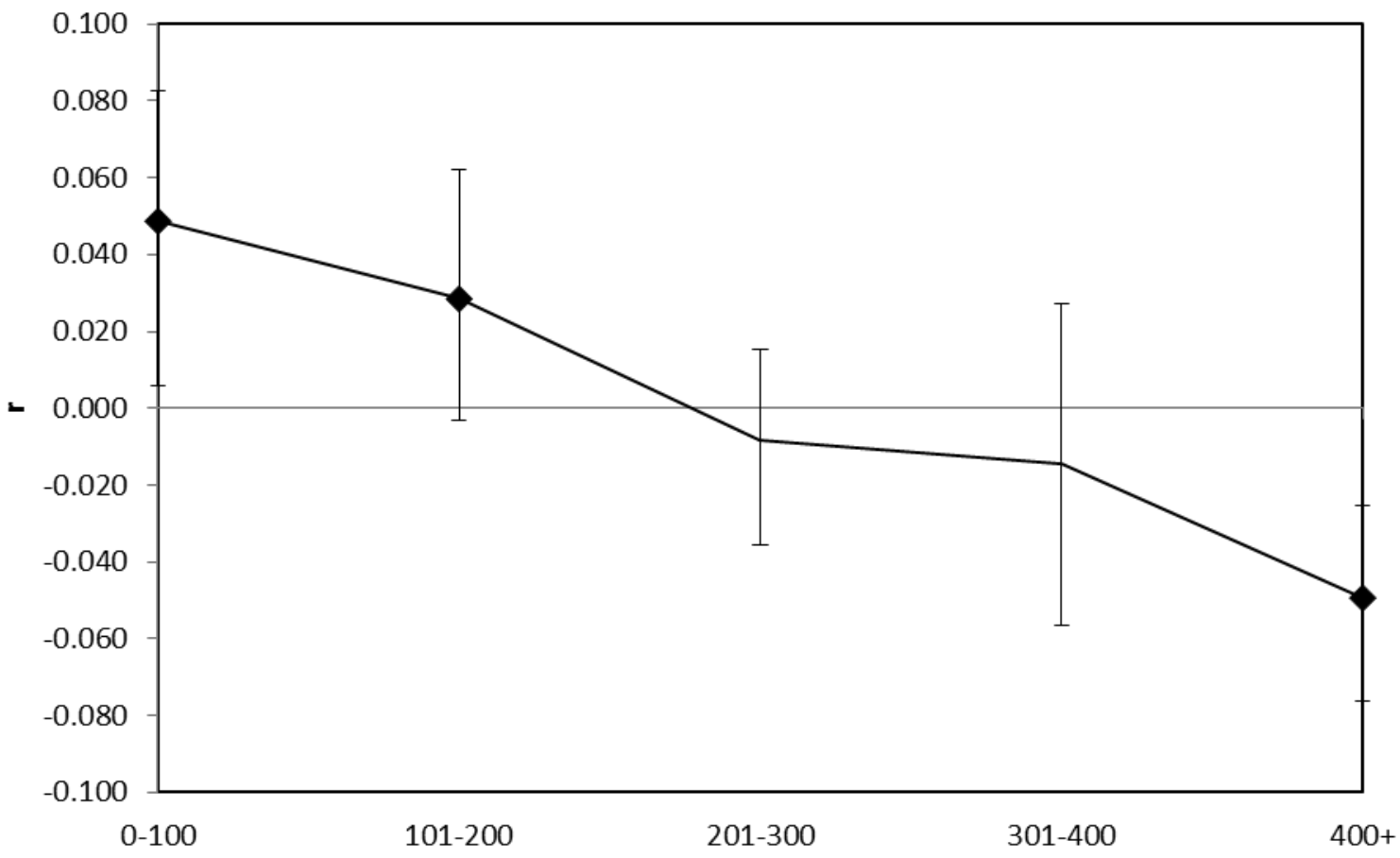



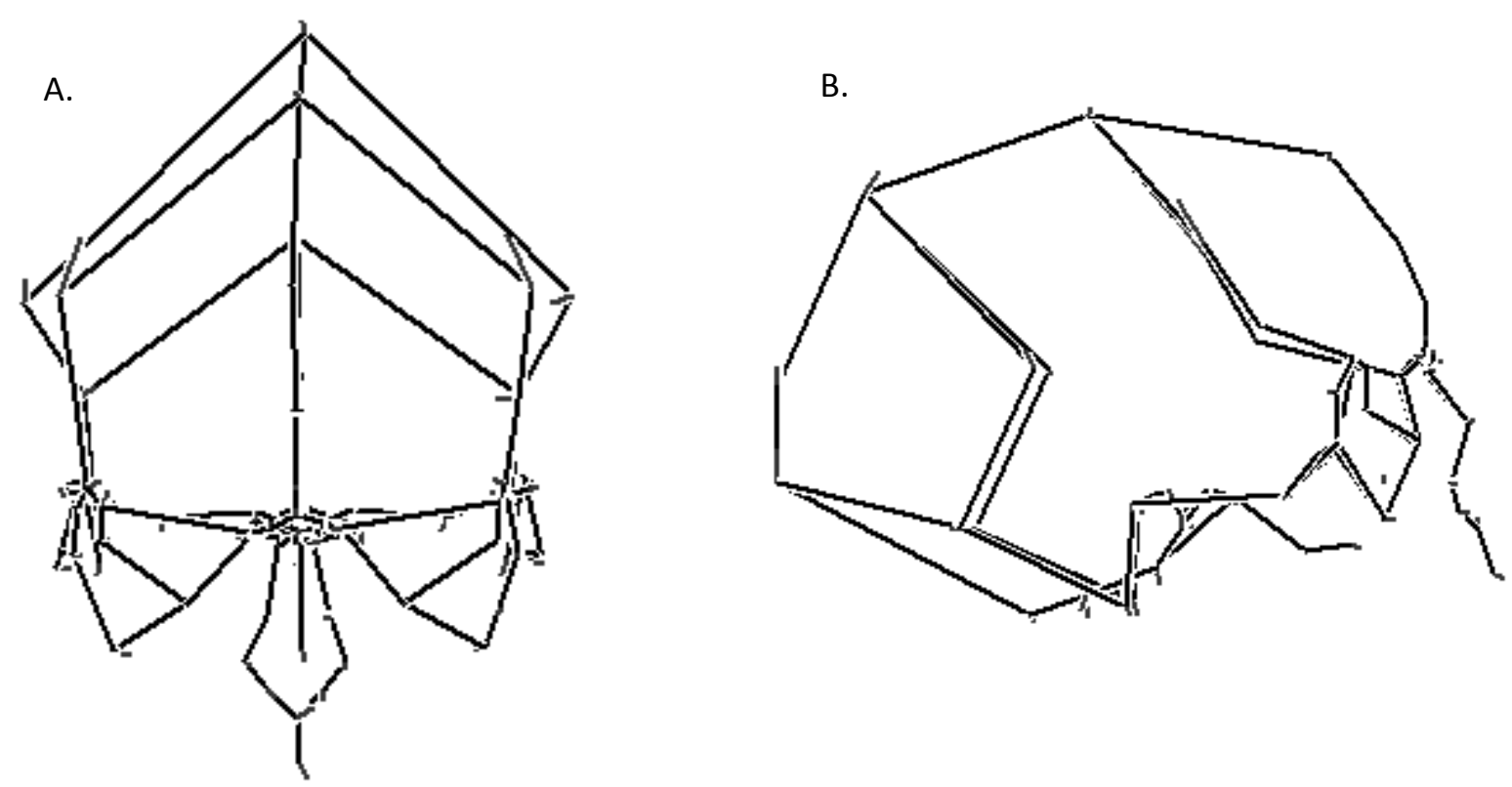